\title{
Consideration of the reference value and number of measurements of the urinary sodium-to-potassium ratio based on the prevalence of untreated home hypertension: TMM Cohort Study
}

\author{
Mana Kogure ${ }^{1,2} \cdot$ Tomohiro Nakamura ${ }^{1,2} \cdot$ Naho Tsuchiya $^{1,3} \cdot$ Takumi Hirata $^{1,4} \cdot$ Kotaro Nochioka $^{1,2,5}$. \\ Akira Narita $^{1,2} \cdot$ Rieko Hatanaka $^{1,2} \cdot$ Fumi Itabashi $^{1} \cdot$ Ikumi Kanno $^{1,2} \cdot$ Taku Obara $^{1,2,5} \cdot$ Michihiro Satoh $^{1,6}$. \\ Hirohito Metoki ${ }^{1,6} \cdot K$ Ken Miyagawa ${ }^{7} \cdot$ Hiroshi Koshimizu ${ }^{7} \cdot$ Sho Nagayoshi ${ }^{7}$ Akira Uruno ${ }^{1,2} \cdot$ Masahiro Kikuya $^{1,8}$. \\ Kichiya Suzuki $^{1,2,5} \cdot$ Naoki Nakaya $^{1,2} \cdot$ Junichi Sugawara ${ }^{1,2,5} \cdot$ Shinichi Kuriyama ${ }^{1,2,9} \cdot$ Ichiro Tsuji $^{1,2} \cdot$ Shigeo Kure $^{1,2,5}$. \\ Atsushi Hozawa ${ }^{1,2}$
}

Received: 26 August 2021 / Revised: 18 November 2021 / Accepted: 30 November 2021 / Published online: 18 January 2022

(c) The Author(s) 2021. This article is published with open access

\begin{abstract}
The sodium-to-potassium $(\mathrm{Na} / \mathrm{K})$ ratio is known to be associated with blood pressure $(\mathrm{BP})$. However, no reference value has been established since the urinary $\mathrm{Na} / \mathrm{K}(\mathrm{uNa} / \mathrm{K})$ ratio is known to have diurnal and day-to-day variations. Therefore, we investigated the number of days required to yield a better association between the morning $\mathrm{UNa} / \mathrm{K}$ ratio and home $\mathrm{BP}$ (HBP) and determined a morning $\mathrm{uNa} / \mathrm{K}$ ratio value that can be used as a reference value in participants who are not taking antihypertensive medication. This was a cross-sectional study using data from the Tohoku Medical Megabank Project Cohort Study. A total of 3122 participants borrowed HBP and $\mathrm{uNa} / \mathrm{K}$ ratio monitors for 10 consecutive days. We assessed the relationship between the morning $\mathrm{uNa} / \mathrm{K}$ ratio from 1 day to 10 days and home hypertension $(\mathrm{HBP} \geq 135 / 85 \mathrm{mmHg})$ using multiple logistic regression models. Although a 1-day measurement of the morning $\mathrm{uNa} / \mathrm{K}$ ratio was positively associated with home hypertension, multiple measurements of the morning $\mathrm{uNa} / \mathrm{K}$ ratio were strongly related to home hypertension. The average morning $\mathrm{uNa} / \mathrm{K}$ ratio was relatively stable after 3 days (adjusted odds ratio of home hypertension per unit increase in the $\mathrm{uNa} / \mathrm{K}$ ratio for more than 3 days: 1.19-1.23). In conclusion, there was no threshold for the $\mathrm{uNa} / \mathrm{K}$ ratio, and the morning $\mathrm{uNa} / \mathrm{K}$ ratio was linearly associated with home hypertension. The $\mathrm{Na} / \mathrm{K}$ ratio 2.0 calculated from the Dietary Reference Intakes for Japanese might be a good indication. Regarding the stability of the association between the morning $\mathrm{uNa} / \mathrm{K}$ ratio and $\mathrm{BP}$, more than 3 days of measurements is desirable.
\end{abstract}

Keywords Home hypertension $\cdot$ Morning urinary $\mathrm{Na} / \mathrm{K}$ ratio $\cdot$ Multiple measurements $\cdot$ Reference value $\cdot \mathrm{TMM} \mathrm{Cohort}$ Study

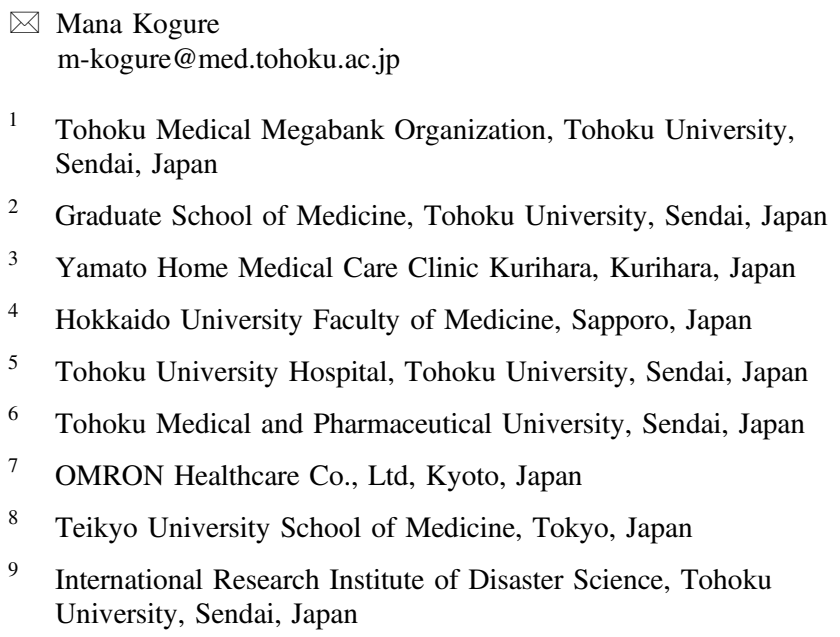

\section{Introduction}

High blood pressure (BP) leads to major health risks, such as heart disease and stroke [1]. In Japan, the estimated number of people with hypertension in 2010 was 43 million [2]. Therefore, the prevention of hypertension is a crucial issue.

It is widely reported that high sodium (Na) and potassium $(\mathrm{K})$ intake are known to be related to high and low BP, respectively [3-7]. In recent years, the balance between $\mathrm{Na}$ and $\mathrm{K}$ intake $(\mathrm{Na} / \mathrm{K}(\mathrm{mol})$ ratio) has received significant attention. It has been reported that the $\mathrm{Na} / \mathrm{K}$ ratio is associated with BP [8-13].

Recently, OMRON Healthcare Co., Ltd. (Fig. 1, HEU001F; OMRON Healthcare Co., Ltd., Kyoto, Japan) 


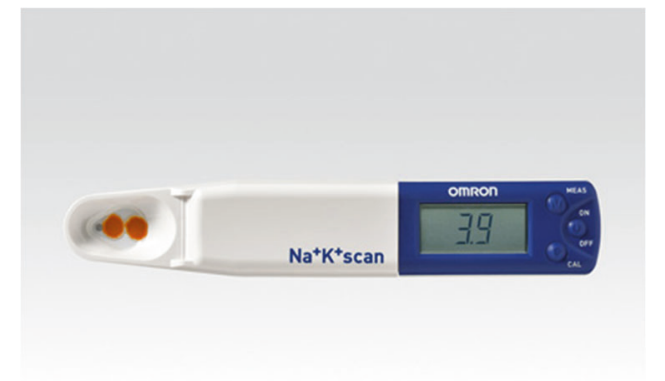

Fig. 1 Handy-sized urinary Na/K ratio monitor (HEU-001F; OMRON Healthcare Co., Ltd., Kyoto, Japan)

developed a handy-sized urinary $\mathrm{Na} / \mathrm{K}$ ratio monitor that can quickly and easily measure the $\mathrm{Na} / \mathrm{K}$ ratio in urine samples. If a handy-sized monitor can be used, it is expected that the urinary $\mathrm{Na} / \mathrm{K}$ ratio can be controlled at home or during a health checkup. Therefore, it is necessary to consider a reference value of the urinary $\mathrm{Na} / \mathrm{K}$ ratio.

However, the urinary $\mathrm{Na} / \mathrm{K}$ ratio is known to have diurnal and day-to-day variations, and it is difficult to set the reference value for the casual urinary $\mathrm{Na} / \mathrm{K}$ ratio. A previous study reported that the casual urinary $\mathrm{Na} / \mathrm{K}$ ratio was higher in the morning and evening than during the daytime [14]. For dayto-day variation, another study showed that although a single measurement of the urinary $\mathrm{Na} / \mathrm{K}$ ratio fairly correlated with seven consecutive 24-h urine samples, six random casual urine samples on different days were well correlated with $\mathrm{Na} /$ $\mathrm{K}$ ratios from seven consecutive 24-h urine samples [15]. This finding was also supported by our previous report that multiple measurements of the $\mathrm{Na} / \mathrm{K}$ ratio correlated with home hypertension better than a single measurement [12].

Thus, to overcome the limitations of diurnal and day-today variations, the following two points should be considered: (1) information should be obtained on the urinary $\mathrm{Na} / \mathrm{K}$ ratio with limited measurement times and (2) information should be obtained on the urinary $\mathrm{Na} / \mathrm{K}$ ratio of multiple measurements. However, there have been no reports of large populations that have satisfied these points.

Thus, in this study, we investigated the number of days required to yield a better association between urinary $\mathrm{Na} / \mathrm{K}$ ratio measurements in the morning and $\mathrm{BP}$ and what morning urinary $\mathrm{Na} / \mathrm{K}$ ratio value can be used as a reference value in participants who are not taking antihypertensive medication.

\section{Methods}

\section{Participant recruitment}

This study was a cross-sectional study using data from the Tohoku Medical Megabank Project Cohort Study (TMM
Cohort Study), which in 2011, aimed to comprehend and address the mental and physical impacts of the Great East Japan Earthquake. Furthermore, this study sought to improve health and medical care in this community. All participants were community residents of the Miyagi or Iwate prefectures and were recruited for this study between May 2013 and March 2016 (Approval number of the Ethical Review Board: 2019-4-065, HG H25-2) [16, 17].

Those who participated in the baseline survey of the TMM Cohort Study were invited to complete a secondary survey (i.e., Repeat assessment center-based survey during second period). Starting in June 2017, the participants could visit any of the seven Community Support Centers within Miyagi Prefecture to complete Repeat assessment centerbased survey during second period. We also began a collaborative study in June 2017 with OMRON Healthcare Co., Ltd. for participants in Repeat assessment center-based survey during second period (June 2017-March 2021). At four of the seven Community Support Centers, we loaned urinary $\mathrm{Na} / \mathrm{K}$ ratio monitors and $\mathrm{BP}$ measuring devices to the participants (three centers started in June 2017, and one center started in June 2020). Of the 15,554 participants who agreed to Repeat assessment center-based survey during second period at three Community Support Centers before 7 April 2020, 7887 participants agreed to participate in the collaborative study with OMRON Healthcare Co., Ltd. (response rate: $50.7 \%$ ). All participants provided written, informed consent to participate in this study, as approved by the Institutional Review Board of Tohoku Medical Megabank Organization (Approval number: 2020-4-026).

\section{Inclusion/exclusion criteria}

Of the 7887 participants who borrowed both urinary $\mathrm{Na} / \mathrm{K}$ ratio monitors and $\mathrm{BP}$ measuring devices, those with no data on morning urinary $\mathrm{Na} / \mathrm{K}$ ratios for 10 consecutive days ( $n=3564)$, home blood pressure (HBP) in the morning $(n=22)$, information on treatment for hypertension $(n=146)$, listed height or weight $(n=14)$, and reported alcohol status $(n=16)$ were excluded from the analyses. Additionally, we excluded participants who were under treatment for hypertension $(n=1003)$. As a result, 3122 participants fulfilled all the criteria and had their data included in the analyses.

\section{Urinary $\mathrm{Na} / \mathrm{K}$ ratio data collection}

In this survey, participants were provided handy-sized urinary $\mathrm{Na} / \mathrm{K}$ ratio monitors (HEU-001F; OMRON Healthcare Co., Ltd., Kyoto, Japan) for 10 days. This monitor can be used as a noninvasive, self-monitoring device for assessing the urinary $\mathrm{Na} / \mathrm{K}$ ratio $[18,19]$. These monitors automatically recorded the $\mathrm{Na} / \mathrm{K}$ ratio measurement values in the device's memory. 
The participants measured urinary $\mathrm{Na} / \mathrm{K}$ ratios by themselves in the morning after waking up and in the evening before going to sleep. The staff at each Community Support Center provided face-to-face instructions on how to use the urinary $\mathrm{Na} / \mathrm{K}$ ratio monitors to each participant; the participants were also requested not to lend the monitor to any other person. In addition, the staff calibrated and checked the sensitivity of the sensors before providing the $\mathrm{Na} / \mathrm{K}$ ratio monitors to the participants. The authors conducted a preliminary validation test of the $\mathrm{Na} / \mathrm{K}$ ratio monitor before the start of this study. The quality criteria of the $\mathrm{Na} / \mathrm{K}$ ratio monitor is that the standard deviation (S.D.) of the calibration solution $(\mathrm{Na} / \mathrm{K}=4.0)$ measured after sensor calibration is within $\pm 10 \%$. In the preliminary validation test, six $\mathrm{Na} / \mathrm{K}$ monitors were calibrated only on the first day, and the calibration solution $(\mathrm{Na} / \mathrm{K}=4.0)$ was measured for 10 days without calibration. As a consequence, the mean value of the $\mathrm{Na} / \mathrm{K}$ ratio was $3.97 \pm 0.29$ (i.e., the S.D. was $\pm 7.3 \%$, unpublished data). From the above, it was confirmed that the result was within the range of quality assurance even if the calibration was conducted only on the first day. The monitors were returned to the Community Support Center by mail, and data from the monitors were uploaded to the Tohoku Medical Megabank Organization (ToMMo) network.

\section{HBP data collection}

In this study, the participants were provided BP monitors (HEM-7080IC; OMRON Healthcare Co., Ltd., Kyoto, Japan) at home for 10 days during the same period of measuring urinary $\mathrm{Na} / \mathrm{K}$ ratios. The participants personally measured their HBP in the morning after waking up and in the evening before going to sleep. In the morning, the participants were directed to take their HBP within $1 \mathrm{~h}$ after waking up, after urination, and before taking drugs or eating breakfast. In the evening, the participants measured their HBP in a seated position before going to sleep. After 10 days, the participants returned the BP monitors to the Community Support Center by mail. The BP monitor data were uploaded to the ToMMo network. The average HBP in the morning for 10 days was used for all analyses. Information on treatment for hypertension was obtained using a self-report questionnaire. The participants answered one question with the following options: 1 . Ever diagnosed with hypertension [(a) under treatment for hypertension, (b) withdrawal of hypertension treatment, (c) under lifestyle modification without medication, and (d) under observation without medication] or 2. Has never been diagnosed with hypertension. In this study, the participants using antihypertensive medication were excluded from the analysis because their $\mathrm{Na} / \mathrm{K}$ ratio values would be strongly affected by antihypertensive medication. Home hypertension was defined as a systolic BP (SBP) $\geq 135 \mathrm{mmHg}$ and/or a diastolic BP (DBP) $\geq 85 \mathrm{mmHg}$ [7].

\section{Covariate factors}

We included potential confounding factors such as age, sex, body mass index (BMI), and drinking status. Age was determined at the time of consent for the secondary survey. Sex was identified using the information provided in the consent form. BMI was calculated from the height and weight obtained from the self-administered questionnaire. BMI was calculated using the following formula: weight $(\mathrm{kg}) /$ height $\left(\mathrm{m}^{2}\right)$.

Alcohol drinking status (frequency and amount per day) was determined using a self-administered questionnaire and was classified into the following four categories: currentdrinker, ex-drinker, never-drinker, and unable to drink constitutionally. The type of alcohol was classified into the following six categories: sake, distilled spirits, shochubased beverages, beer, whiskey, and wine. The frequency of alcohol intake was classified into the following six categories: almost never, 1-3 days/month, 1-2 days/week, 3-4 days/week, 5-6 days/week, or daily. The participants answered how much of each type of alcohol they drank. Each type of alcohol intake was multiplied by the frequency and amount and converted to ethanol. The drinking amount was classified into the following four categories: neverdrinker, ex-drinker, $<23 \mathrm{~g}$ per day, and $\geq 23 \mathrm{~g}$ per day. We determined the cutoff value of the alcohol amount to be $23 \mathrm{~g}$ because it is the traditional Japanese unit of sake.

\section{Calculations and statistical analysis}

In this study, we used morning urinary $\mathrm{Na} / \mathrm{K}$ ratio data. It has been reported that urination is more frequent in the morning than at other times of the day under free-living conditions in the wakeful state [14]. Moreover, it was also reported that the most common time of day for home BP monitoring in patients under treatment for hypertension was in the morning [20]. Moreover, most patients with lifestylerelated diseases in Japan seem to take their daily medication in the morning hours despite there being no restrictions on taking medication at a specific time slot [21].

As mentioned above, if the urinary $\mathrm{Na} / \mathrm{K}$ ratio monitor is introduced in households as a self-monitoring tool in the future, it is expected that some measurements will be taken in the morning in conjunction with a home $\mathrm{BP}$ monitor. We used the average morning urinary $\mathrm{Na} / \mathrm{K}$ ratio from 1 day to 10 days. The daily morning urinary $\mathrm{Na} / \mathrm{K}$ ratio was calculated as the average morning urinary $\mathrm{Na} / \mathrm{K}$ ratios. If multiple measurements of the urinary $\mathrm{Na} / \mathrm{K}$ ratio were taken at the same time of day, the first measurement value was 
adopted. Measurements from 4 a.m. to 10 a.m. were taken as morning measurements.

Regarding the baseline characteristics, we classified participants' average morning urinary $\mathrm{Na} / \mathrm{K}$ ratios at 10 days into nine categories $(<1.0,1.0-1.9,2.0-2.9$, $3.0-3.9,4.0-4.9,5.0-5.9,6.0-6.9,7.0-7.9$, and $\geq 8.0)$. We tested for trends in the morning urinary $\mathrm{Na} / \mathrm{K}$ ratio based on participants' characteristics, including age, sex, BMI, morning urinary $\mathrm{Na} / \mathrm{K}$ ratios for 10 days, SBP, DBP, drinking status, home hypertension, and information on treatment for hypertension. We performed trend tests to evaluate the linear relationship between the morning urinary $\mathrm{Na} / \mathrm{K}$ ratio and the variables mentioned above. We used a general linear model for the continuous variables of age, BMI, morning urinary $\mathrm{Na} / \mathrm{K}$ ratio for 10 days, SBP, and DBP and a logistic regression model for the categorical variables of sex, drinking status, home hypertension, and information on treatment for hypertension.

To examine the relationship between morning urinary $\mathrm{Na} / \mathrm{K}$ ratio for 10 days and HBP in detail, we performed an analysis of covariance to calculate the adjusted mean HBP. The morning urinary $\mathrm{Na} / \mathrm{K}$ ratio was classified into nine categories. Additionally, we stratified the participants into two groups: ever diagnosed with hypertension $(n=496)$ and never diagnosed with hypertension $(n=2628)$ to consider the influence of treatment status on hypertension. Furthermore, we tested for linear trends in HBP according to the nine categories of morning urinary $\mathrm{Na} / \mathrm{K}$ ratios. In this analysis, we included age, BMI, and alcohol intake as potential confounding factors.

To examine the relationship between the morning urinary $\mathrm{Na} / \mathrm{K}$ ratio from 1 day to 10 days and home hypertension, we used multiple logistic regression models and calculated adjusted odds ratios (aORs) with 95\% confidence intervals. The morning urinary $\mathrm{Na} / \mathrm{K}$ ratio was classified into eight categories $(<2.0,2.0-2.9,3.0-3.9$, $4.0-4.9,5.0-5.9,6.0-6.9,7.0-7.9$, and $\geq 8.0$ ) because there were a few participants with a morning urinary $\mathrm{Na} / \mathrm{K}$ ratio of less than 1.0. Adjusted odds ratio $P$ values for linear trends were calculated using the nine categories of urinary $\mathrm{Na} / \mathrm{K}$ ratios. We included potential confounding factors in the model, such as age, sex, BMI, and drinking status.

We calculated the area under the receiver operating characteristic curve (AUROC) to assess whether multiple measurements of morning urinary $\mathrm{Na} / \mathrm{K}$ ratios increased the ability to predict home hypertension.

Furthermore, to consider the reference value of the urinary $\mathrm{Na} / \mathrm{K}$ ratio, the salt equivalent and potassium intake, which are the tentative dietary goal for preventing life-style related diseases (DG) in the Dietary Reference Intakes for Japanese, 2020 [22], were converted into $\mathrm{mEq} / \mathrm{day}$, and the urinary $\mathrm{Na} / \mathrm{K}$ ratio was calculated. The urinary excretion of
$\mathrm{Na}$ and $\mathrm{K}$ was calculated assuming $86 \%$ and $77 \%$ of the total intake, respectively [23].

All analyses were performed using SAS version 9.4 for Windows (SAS Inc., Cary, NC, USA).

\section{Results}

We analyzed 820 men and 2302 women who did not take antihypertensive medication. Table 1 shows the baseline characteristics of the participants not taking antihypertensive medication grouped by their average 10-day morning urinary $\mathrm{Na} / \mathrm{K}$ ratio. Younger participants, men, those with a higher BMI, those with a higher SBP, those with a higher DBP, and current drinkers ( $\geq 23 \mathrm{~g} /$ day) were more likely to have an increased morning urinary $\mathrm{Na} / \mathrm{K}$ ratio $(P$ for linear trend $<0.05$ ). The proportion of participants who had ever been diagnosed with hypertension was $50.0 \%$ in the group with a morning urinary $\mathrm{Na} / \mathrm{K}$ ratio $<1.0$.

Figure 2 shows the relationship between the 10-day average morning urinary $\mathrm{Na} / \mathrm{K}$ ratio and the adjusted mean home SBP. Although home SBP was high in the group with a morning urinary $\mathrm{Na} / \mathrm{K}$ ratio $<1.0$, it was positively associated with the morning urinary $\mathrm{Na} / \mathrm{K}$ ratio $(P$ for linear trend $<0.001$ ).

Figure 3 shows the relationship between the 10-day average morning urinary $\mathrm{Na} / \mathrm{K}$ ratio and the adjusted mean home SBP among the 2626 participants who never been diagnosed with hypertension. The morning urinary $\mathrm{Na} / \mathrm{K}$ ratio was positively associated with home SBP $(P$ for linear trend $<0.001$ ).

Figure 4 shows the relationship between the 10-day average morning urinary $\mathrm{Na} / \mathrm{K}$ ratio and the adjusted mean home SBP among the 496 participants who had ever been diagnosed with hypertension. Although home SBP was high in the group with a morning urinary $\mathrm{Na} / \mathrm{K}$ ratio $<1.0$, it was positively associated with the morning urinary $\mathrm{Na} / \mathrm{K}$ ratio ( $P$ for linear trend $<0.001$ ).

Table 2 shows the relationship between the average morning urinary $\mathrm{Na} / \mathrm{K}$ ratios from Day 1 to Day 10 and home hypertension. Although a 1-day measurement of the morning urinary $\mathrm{Na} / \mathrm{K}$ ratio was positively associated with home hypertension, multiple measurements of the morning urinary $\mathrm{Na} / \mathrm{K}$ ratio were related to home hypertension. In addition, the aOR of home hypertension per unit increase in the average morning urinary $\mathrm{Na} / \mathrm{K}$ ratio increased from Day 1 to Day 3; however, the aOR was stable after 3 days (range 1.19-1.23). Similarly, the AUROC was increased according to the measurement days. The AUROC was almost stable after 3 days $(A U R O C=0.764-0.768$ ). The AUROC without the morning urinary $\mathrm{Na} / \mathrm{K}$ ratio was 0.753 .

The urinary $\mathrm{Na} / \mathrm{K}$ ratio was calculated as $\mathrm{mEq} / \mathrm{day}$ based on Na intake and $\mathrm{K}$ intake, which are the DG in the Dietary 


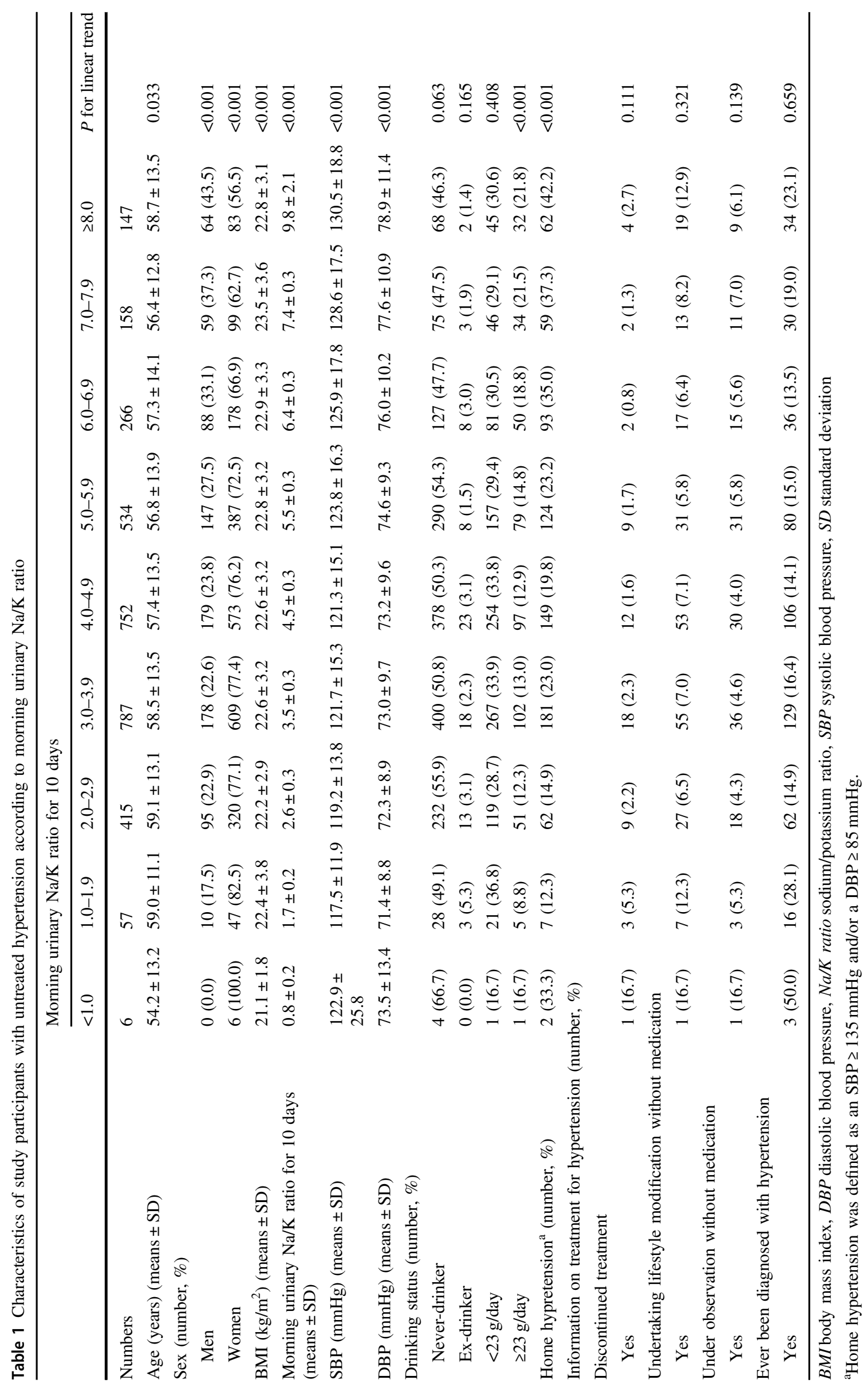




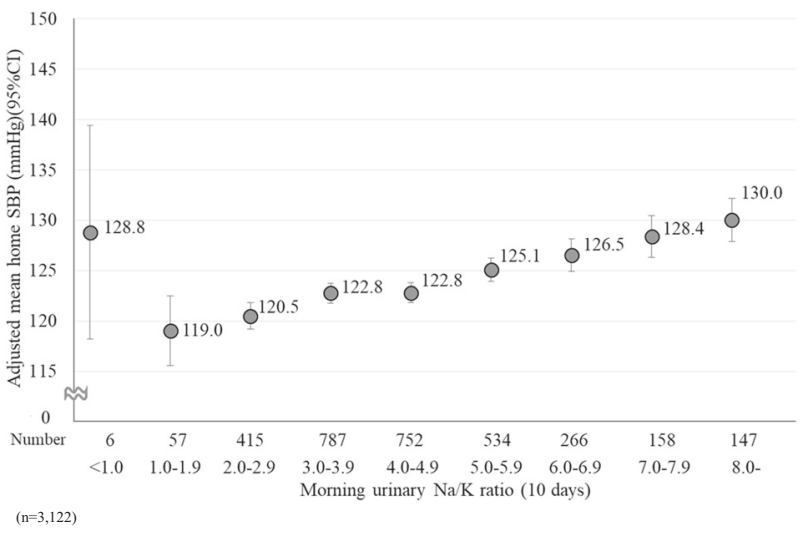

Fig. 2 The relationship between the 10-day average morning urinary $\mathrm{Na} / \mathrm{K}$ ratio and the adjusted mean home SBP. The adjusted mean home SBP was calculated from the analysis of covariance. The error bars represent a $95 \%$ confidence interval

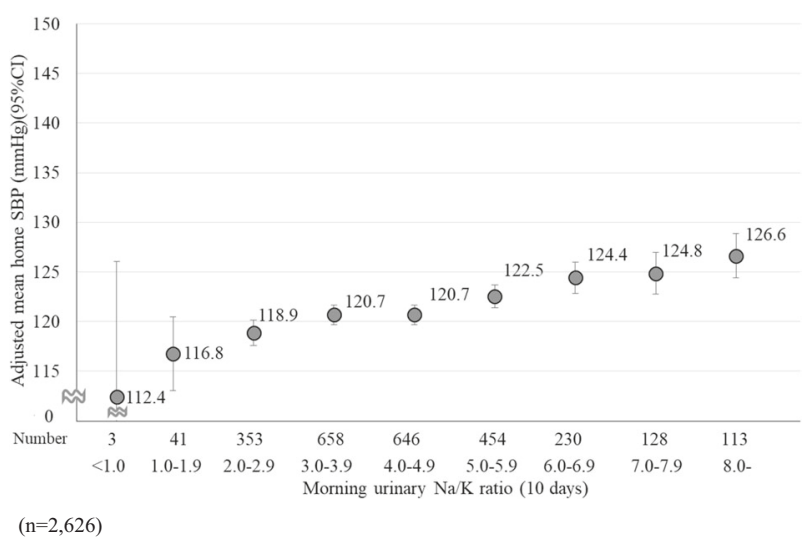

Fig. 3 The relationship between the 10-day average morning urinary $\mathrm{Na} / \mathrm{K}$ ratio and the adjusted mean home SBP among the 2626 participants who had never been diagnosed with hypertension. The adjusted mean home SBP was calculated from the analysis of covariance. The error bars represent a $95 \%$ confidence interval

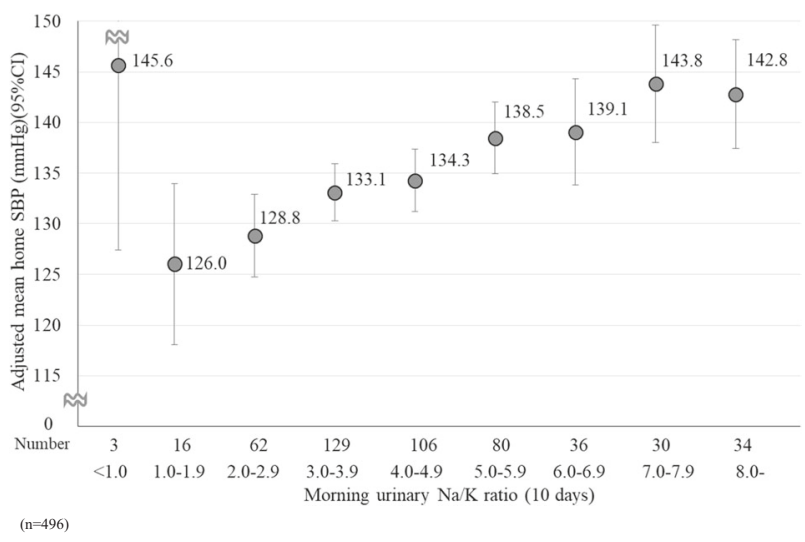

Fig. 4 The relationship between the 10-day average morning urinary $\mathrm{Na} / \mathrm{K}$ ratio and the adjusted mean home SBP among the 496 participants who had ever been diagnosed with hypertension. The adjusted mean home SBP was calculated from the analysis of covariance. The error bars represent a 95\% confidence interval
Reference Intakes for Japanese, 2020. The DG of a salt equivalent was $7.5 \mathrm{~g} /$ day in adult men and $6.5 \mathrm{~g} / \mathrm{day}$ in adult women. These values corresponded to $128.4 \mathrm{mEq} / \mathrm{day}$ and $111.3 \mathrm{mEq} / \mathrm{day}$ of Na, respectively. Similarly, the DG of K intake was $3000 \mathrm{mg} /$ day in adult men and $2600 \mathrm{mg} /$ day in women. These values corresponded to $76.7 \mathrm{mEq} / \mathrm{day}$ and $66.5 \mathrm{mEq} / \mathrm{day}$, respectively. The urinary excretion of $\mathrm{Na}$ and $\mathrm{K}$ was calculated assuming $86 \%$ and $77 \%$ of the total intake, respectively (Na: $110.4 \mathrm{mEq} /$ day, K: $59.1 \mathrm{mEq} /$ day in men; Na: $95.7 \mathrm{mEq} /$ day, $\mathrm{K}: 51.2 \mathrm{mEq} / \mathrm{day}$ in women). Thus, the urinary $\mathrm{Na} / \mathrm{K}$ ratio was 1.87 for both men and women.

\section{Discussion}

We investigated the number of days required to yield a better association between the urinary $\mathrm{Na} / \mathrm{K}$ ratio measured in the morning and $\mathrm{BP}$ and what morning urinary $\mathrm{Na} / \mathrm{K}$ ratio value can be used as a reference value in participants who are not taking antihypertensive medication.

Although a 1-day measurement of the morning urinary $\mathrm{Na} / \mathrm{K}$ ratio was positively associated with home hypertension, multiple measurements of the morning urinary $\mathrm{Na} / \mathrm{K}$ ratio were strongly related to home hypertension. In addition, although the relationship was stronger for measurements including more days, the aOR of home hypertension per unit increase in the average morning urinary $\mathrm{Na} / \mathrm{K}$ ratio was relatively stable after 3 days. A previous study reported that the mean urinary $\mathrm{Na} / \mathrm{K}$ ratio of 4-7 days on different days correlated with a 1-2 day 24-h urinary $\mathrm{Na} / \mathrm{K}$ ratio with high BP [24]. Another study reported that the correlation coefficient increased up to 4 days, and the urinary $\mathrm{Na} / \mathrm{K}$ ratio was relatively stable at $\geq 0.80$ [15]. Our results were consistent with those of previous studies. There was no threshold for the urinary $\mathrm{Na} / \mathrm{K}$ ratio, and the morning urinary $\mathrm{Na} / \mathrm{K}$ ratio was linearly associated with home hypertension. However, if the urinary $\mathrm{Na} / \mathrm{K}$ ratio measurement is introduced into home or health checkups in the future, a reference value for the urinary $\mathrm{Na} / \mathrm{K}$ ratio is necessary.

The World Health Organization guidelines recommend an $\mathrm{Na} / \mathrm{K}$ ratio of approximately less than 1.0 for health benefits $[3,4]$. However, considering the salt and $\mathrm{K}$ intake in Japan, it is expected to be difficult to reduce the $\mathrm{Na} / \mathrm{K}$ ratio to less than 1.0 in real life.

In contrast, the risk of cardiovascular disease has been reported to be low even at urinary $\mathrm{Na} / \mathrm{K}$ ratio below 2.0 [25]. Furthermore, the urinary $\mathrm{Na} / \mathrm{K}$ ratio, which is calculated by converting the urinary excretion of $\mathrm{Na}$ and $\mathrm{K}$ from the $\mathrm{Na}$ and $\mathrm{K}$ targeted intake in the Dietary Reference Intakes for Japanese, 2020, was approximately 2.0 for both men and women. Therefore, we consider it suitable to aim for a urinary $\mathrm{Na} / \mathrm{K}$ ratio of less than 2.0 at this point. 


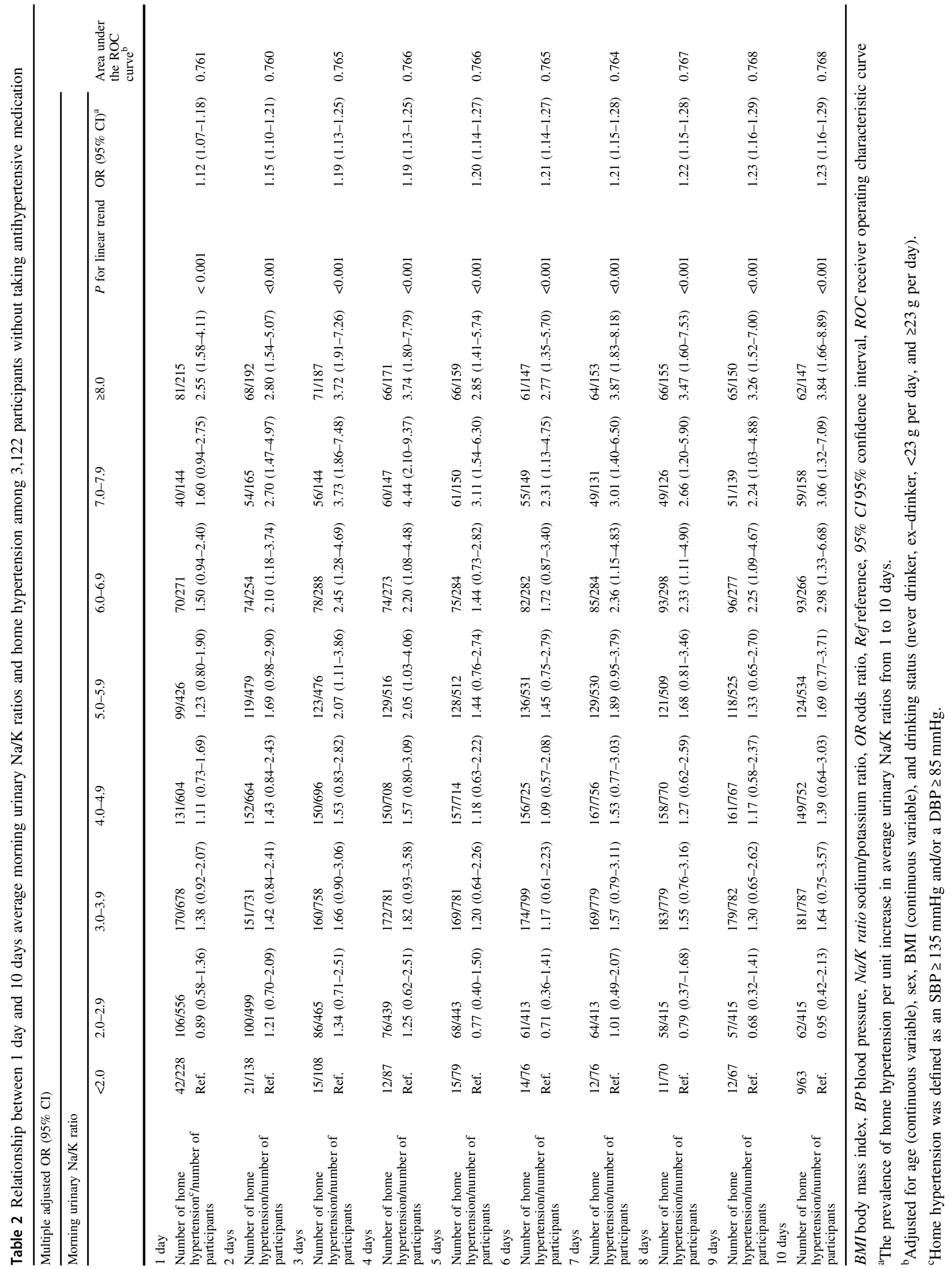


It is necessary to consider how to define the reference value by using data on $\mathrm{Na}$ and $\mathrm{K}$ intake, which are set as target values in other guidelines, or by using the median value as the cutoff point based on the distribution of the urinary $\mathrm{Na} / \mathrm{K}$ ratio measured multiple times in a large population, such as in this study.

Our results regarding the relationship between the urinary $\mathrm{Na} / \mathrm{K}$ ratio and $\mathrm{BP}$ were consistent with those of previous studies [8-13]. However, although the difference was not statistically significant, home SBP was higher in the group with a morning urinary $\mathrm{Na} / \mathrm{K}$ ratio less than 1.0 compared to the other groups' morning urinary $\mathrm{Na} / \mathrm{K}$ ratio. We considered reasons why home SBP was higher in the group with a morning urinary $\mathrm{Na} / \mathrm{K}$ ratio less than 1.0. First, some medications might affect the urinary $\mathrm{Na} / \mathrm{K}$ ratio and BP. The TMM Cohort Study obtained information about medication status (including the duration, frequency, and amount of medication used) using a self-report questionnaire. In terms of medication status, one participant in the group with a morning urinary $\mathrm{Na} / \mathrm{K}$ ratio less than 1.0 who had ever been diagnosed with hypertension was taking glycyrrhizin supplements. It is also known that glycyrrhizin supplements may cause pseudoaldosteronism. These results suggested that home SBP was higher in the group with a morning urinary $\mathrm{Na} / \mathrm{K}$ ratio less than 1.0. Previous reports have shown a high correlation between the urinary $\mathrm{Na} / \mathrm{K}$ ratio and 24-h urinary $\mathrm{Na} / \mathrm{K}$ ratio in chronic kidney disease (CKD) stages 1-3 but not in CKD stages 4-5 because some CKD stages 4-5 patients take diuretics that affect the urinary $\mathrm{Na} / \mathrm{K}$ ratio; it is difficult to evaluate multiple measurements of the urinary $\mathrm{Na} / \mathrm{K}$ ratio [26]. Furthermore, a recent study reported that lower urinary $\mathrm{Na} / \mathrm{K}$ ratio might detect primary hyperaldosteronism [27]. Thus, we considered that participants with extremely low urinary $\mathrm{Na} / \mathrm{K}$ ratio need to be cautious because they may be affected by medications. Another possible reason might be reverse causality; some participants with high $\mathrm{BP}$ might have already reduced their salt intake and/or increased their vegetable intake. This possibility was supported by Fig. 3, i.e., we excluded participants who had been diagnosed with hypertension in the past and showed a linear association between the morning urinary $\mathrm{Na} / \mathrm{K}$ ratio and home SBP.

The present study has some strengths. First, this is the first study to investigate the reference value of the morning urinary $\mathrm{Na} / \mathrm{K}$ ratio for hypertension in a large population using data on the $\mathrm{Na} / \mathrm{K}$ ratio with a limited measurement time and on multiple measurements to consider diurnal variation and day-to-day variation. Finally, we included various confounding factors.

Our study also has some limitations. First, since this study had a cross-sectional design, it is difficult to confirm reverse causality. Participants with high BP might have developed good behaviors, such as reducing their salt and alcohol intake. Therefore, we considered that lifestyle modifications for high BP would lead to an underestimated relationship between a high $\mathrm{Na} / \mathrm{K}$ ratio and home hypertension. Second, we could not consider seasonal variations in home $\mathrm{BP}$ and the urinary $\mathrm{Na} / \mathrm{K}$ ratio in this study. It has been reported that the urinary $\mathrm{Na} / \mathrm{K}$ ratio and home $\mathrm{BP}$ exhibit seasonal variations $[28,29]$. If seasonal variations were considered in this analysis, the relationship between the urinary $\mathrm{Na} / \mathrm{K}$ ratio and home $\mathrm{BP}$ might have been stronger. Finally, we did not directly assess whether the predictive power of the long-term casual urinary $\mathrm{Na} / \mathrm{K}$ ratio might be equivalent to that of a $24-\mathrm{h}$ urinary $\mathrm{Na} / \mathrm{K}$ ratio as the gold standard. However, a single measurement of the urinary $\mathrm{Na} / \mathrm{K}$ ratio fairly correlated with seven consecutive 24-h urine samples, and six random casual urine samples on different days were well correlated with $\mathrm{Na} / \mathrm{K}$ ratios from seven consecutive 24-h urine samples [15]. Therefore, we believe that our findings are applicable.

In conclusion, we found that there was no threshold for the urinary $\mathrm{Na} / \mathrm{K}$ ratio, and the morning urinary $\mathrm{Na} / \mathrm{K}$ ratio was linearly associated with home hypertension. However, participants with extremely low urinary $\mathrm{Na} / \mathrm{K}$ ratio need to be cautious in following the situation of the population. In addition, it is necessary to consider the reference value while defining a cutoff based on the distribution of the population and utilizing other guidelines. At present, the $\mathrm{Na} / \mathrm{K}$ ratio of 2.0 , calculated from the Dietary Reference Intakes for Japanese, 2020, might be a good indication. Regarding the stability of the association between the morning urinary $\mathrm{Na} / \mathrm{K}$ ratio and $\mathrm{BP}$, it would be desirable to measure it for more than 3 days.

Acknowledgements This study was conducted by ToMMo in collaboration with OMRON Healthcare Co., Ltd. The authors sincerely express their gratitude to the people of Japan and those worldwide for their valuable support to the areas affected by the Great East Japan Earthquake disaster. We thank the members of ToMMo, including the Genome Medical Research Coordinators, office and administrative personnel, and software engineers for their assistance with this project. We also thank all the members of OMRON Healthcare Co., Ltd.

Author contributions AH: study concept and design. MK, TN, NT, TH, AN, RH, FI, IK, TO, AU, MK, KS, NN, JS, SK, IT, SK, and AH: data collection. All authors: analysis and interpretation of data. MK and AH: drafting article. All authors contributed intellectually to the revision of the article and approved the final version.

Funding This work was supported by Tohoku Medical Megabank Project from MEXT and Japan Agency for Medical Research and development, AMED (under Grant Number JP20km0105001); and OMRON Healthcare Co., Ltd.

\section{Compliance with ethical standards}

Conflict of interest Mana Kogure, Tomohiro Nakamura, Naho Tsuchiya, Takumi Hirata, Fumi Itabashi, Hirohito Metoki, Akira Uruno, Masahiro Kikuya, Naoki Nakaya, Junichi Sugawara, Shinichi 
Kuriyama and Atsushi Hozawa received a grant from OMRON Healthcare Co., Ltd. Ken Miyagawa, Hiroshi Koshimizu and Sho Nagayoshi are employees of OMRON Healthcare Co., Ltd. The other authors declare no competing interests.

Publisher's note Springer Nature remains neutral with regard to jurisdictional claims in published maps and institutional affiliations.

Open Access This article is licensed under a Creative Commons Attribution 4.0 International License, which permits use, sharing, adaptation, distribution and reproduction in any medium or format, as long as you give appropriate credit to the original author(s) and the source, provide a link to the Creative Commons license, and indicate if changes were made. The images or other third party material in this article are included in the article's Creative Commons license, unless indicated otherwise in a credit line to the material. If material is not included in the article's Creative Commons license and your intended use is not permitted by statutory regulation or exceeds the permitted use, you will need to obtain permission directly from the copyright holder. To view a copy of this license, visit http://creativecommons. org/licenses/by/4.0/.

\section{References}

1. Forouzanfar MH, Liu P, Roth GA, Ng M, Biryukov S, Marczak L, et al. Global burden of hypertension and systolic blood pressure of at least 110 to $115 \mathrm{~mm} \mathrm{Hg}, 1990-2015$. JAMA. 2017;317:165-82.

2. Miura K, Nagai M, Ohkubo T. Epidemiology of hypertension in Japan: where are we now? Circ J. 2013;77:2226-31.

3. WHO. Guideline: sodium intake for adults and children. Geneva, World Health Organization (WHO), 2012.

4. WHO. Guideline: potassium intake for adults and children. Geneva: World Health Organization (WHO); 2012.

5. Whelton PK, Carey RM, Aronow WS, Casey DE Jr., Collins KJ, Dennison Himmelfarb C, et al. 2017 ACC/AHA/AAPA/ABC/ ACPM/AGS/APhA/ASH/ASPC/NMA/PCNA guideline for the prevention, detection, evaluation, and management of high blood pressure in adults: executive summary: a report of the american college of cardiology/american heart association task force on clinical practice guidelines. J Am Soc Hypertens. 2018;12:579.

6. Williams B, Mancia G, Spiering W, Agabiti Rosei E, Azizi M, Burnier M, et al. $2018 \mathrm{ESC} / \mathrm{ESH}$ guidelines for the management of arterial hypertension. Eur Heart J. 2018; 3021-104.

7. Umemura S, Arima H, Arima S, Asayama K, Dohi Y, Hirooka Y, et al. The Japanese Society of Hypertension Guidelines for the Management of Hypertension (JSH 2019). Hypertens Res. 2019;42:1235-481.

8. Intersalt Cooperative Research Group. Intersalt: an international study of electrolyte excretion and blood pressure. Results for $24 \mathrm{~h}$ urinary sodium and potassium excretion. BMJ. 1988;297:319-28.

9. Mente A, O'Donnell MJ, Rangarajan S, McQueen MJ, Poirier P, Wielgosz A, et al. Association of urinary sodium and potassium excretion with blood pressure. N Engl J Med. 2014;371:601-11.

10. Tabara Y, Takahashi Y, Kumagai K, Setoh K, Kawaguchi T, Takahashi M, et al. Descriptive epidemiology of spot urine sodium-to-potassium ratio clarified close relationship with blood pressure level: the Nagahama study. J Hypertens. 2015;33:2407-13.

11. Jackson SL, Cogswell ME, Zhao L, Terry AL, Wang CY, Wright $\mathrm{J}$, et al. Association between urinary sodium and potassium excretion and blood pressure among adults in the United States:
National Health and Nutrition Examination Survey, 2014. Circulation. 2018;137:237-46.

12. Kogure M, Hirata T, Nakaya N, Tsuchiya N, Nakamura T, Narita A, et al. Multiple measurements of the urinary sodium-topotassium ratio strongly related home hypertension: TMM Cohort Study. Hypertens Res. 2020;43:62-71.

13. Kogure M, Nakaya N, Hirata T, Tsuchiya N, Nakamura T, Narita A, et al. Sodium/potassium ratio change was associated with blood pressure change: possibility of population approach for sodium/potassium ratio reduction in health checkup. Hypertens Res. 2020. https://doi.org/10.1038/s41440-020-00536-7.

14. Iwahori $\mathrm{T}$, Ueshima $\mathrm{H}$, Torii S, Saito $\mathrm{Y}$, Kondo K, TanakaMizuno S, et al. Diurnal variation of urinary sodium-to-potassium ratio in free-living Japanese individuals. Hypertens Res. 2017;40:658-64

15. Iwahori $\mathrm{T}$, Ueshima $\mathrm{H}$, Miyagawa $\mathrm{N}$, Ohgami N, Yamashita $\mathrm{H}$, Ohkubo T, et al. Six random specimens of daytime casual urine on different days are sufficient to estimate daily sodium/potassium ratio in comparison to 7-day 24-h urine collections. Hypertens Res. 2014;37:765-71.

16. Kuriyama S, Metoki H, Kikuya M, Obara T, Ishikuro M, Yamanaka C, et al. Cohort profile: Tohoku Medical Megabank Project Birth and Three-Generation Cohort Study (TMM BirThree Cohort Study): rationale, progress and perspective. Int $\mathbf{J}$ Epidemiol. 2020;49:18-19m.

17. Hozawa A, Tanno K, Nakaya N, Nakamura T, Tsuchiya N, Hirata $\mathrm{T}$, et al. Study profile of the Tohoku Medical Megabank Community-Based Cohort Study. J Epidemiol. 2021;31:65-76.

18. Iwahori T, Ueshima H, Ohgami N, Yamashita H, Miyagawa N, Kondo $\mathrm{K}$, et al. Effectiveness of a self-monitoring device for urinary sodium-to-potassium ratio on dietary improvement in freeliving adults: a randomized controlled trial. $\mathrm{J}$ Epidemiol. 2018;28:41-7.

19. Yatabe MS, Iwahori T, Watanabe A, Takano K, Sanada H, Watanabe $\mathrm{T}$, et al. Urinary sodium-to-potassium ratio tracks the changes in salt intake during an experimental feeding study using standardized low-salt and high-salt meals among healthy Japanese volunteers. Nutrients. 2017;9:951.

20. Nezu K, Satoh H, Takahashi E, Moriuchi A, Goto T, Kikuchi A. The current state of home blood pressure monitoring in hypertensive patients. Health Eval Promot. 2020;47:352-6. in Japanese

21. Kamei M, Iwahori T, Cai Z, Takeuchi M. Dosing frequency, Adherence, and patient burden in patients with type 2 diabetes mellitus-a web-based survey using an electronic medicine notebook service-. Prog Med. 2020;40:979-87. in Japanese

22. Ministry of Health, Labour and Welfare of Japan. The dietary reference intakes for Japanese, 2020 [accessed 18 Dec 2020]. https://www.mhlw.go.jp/content/10904750/000586553.pdf (in Japanese).

23. Holbrook JT, Patterson KY, Bodner JE, Douglas LW, Veillon C, Kelsay JL, et al. Sodium and potassium intake and balance in adults consuming self-selected diets. Am J Clin Nutr. 1984;40:786-93.

24. Iwahori T, Ueshima H, Torii S, Saito Y, Fujiyoshi A, Ohkubo T, et al. Four to seven random casual urine specimens are sufficient to estimate 24-h urinary sodium/potassium ratio in individuals with high blood pressure. J Hum Hypertens. 2016;30:328-34.

25. Cook NR, Obarzanek E, Cutler JA, Buring JE, Rexrode KM, Kumanyika SK, et al. Joint effects of sodium and potassium intake on subsequent cardiovascular disease: the Trials of Hypertension Prevention follow-up study. Arch Intern Med. 2009;169:32-40.

26. Okuyama Y, Uchida HA, Iwahori T, Segawa H, Kato A, Takeuchi $\mathrm{H}$, et al. The relationship between repeated measurement of casual and 24-h urinary sodium-to-potassium ratio in patients with chronic kidney disease. J Hum Hypertens. 2019;33:286-97. 
27. Segawa H, Higashi A, Masuda I, Yoshii K, Iwahori T, Ueshima H Urinary sodium/potassium ratio as a screening tool for hyperaldosteronism in men with hypertension. Hypertens Res. 2021; https://doi.org/10.1038/s41440-021-00663-9. Epub ahead of print.

28. Tabara Y, Takahashi Y, Kumagai K, Setoh K, Kawaguchi T, Takahashi $\mathrm{M}$, et al. Descriptive epidemiology of spot urine sodiumto-potassium ratio clarified close relationship with blood pressure level: the Nagahama study. J Hypertens. 2015; 33:2407-13.

29. Hanazawa T, Asayama K, Watabe D, Hosaka M, Satoh M, Yasui $\mathrm{D}$, et al. Seasonal variation in self-measured home blood pressure among patients on antihypertensive medications: HOMED-BP study. Hypertens Res. 2017;40:284-90. 